\title{
Spinocerebellar ataxia with axonal neuropathy type 1
}

INSERM

\section{Source}

INSERM. (1999). Orphanet: an online rare disease and orphan drug data base.

Spinocerebellar ataxia with axonal neuropathy type 1. ORPHA:94124

Spinocerebellar ataxia with axonal neuropathy type 1 is a rare, genetic neurological

disorder characterized by a late childhood onset of slowly progressive cerebellar ataxia.

Initial manifestations include weakness and atrophy of distal limb muscles, areflexia and

loss of pain, vibration and touch sensations in upper and lower extremities. Gaze

nystagmus, cerebellar dysarthria, peripheral neuropathy, stepagge gait and pes cavus

develop as disease progresses. Cerebellar atrophy (especially of the vermis) is present in

all affected individuals. Additional reported manifestations include seizures, mild brain atrophy, mild hypercholesterolemia and borderline hypoalbuminemia. 